\title{
O ensino da Língua Materna em projetos PIBID/Pedagogia do Estado de São Paulo
}

\author{
Cristiane Tronquin ${ }^{1}$
}

\section{RESUMO}

Neste artigo, apresentamos os resultados de uma pesquisa em que se buscou investigar as propostas de ensino de língua materna que embasam Projetos realizados no âmbito do Programa Institucional de Bolsa de Iniciação à Docência (PIBID) de Pedagogia, em Instituições de Ensino Superior do Estado de São Paulo. Dentre as vinte e cinco Instituições paulistas que realizam ou realizaram projetos do PIBID/Pedagogia entre 2009 e 2012, identificamos na web 12 produções que contemplam o processo de alfabetização e letramento e/ou o ensino de língua portuguesa nos anos iniciais do Ensino Fundamental $\left(1^{\circ}\right.$ ao $5^{\circ}$ ano). A análise dessas produções evidenciou que, em sua maioria, a abordagem adotada para a formação dos bolsistas é bem coerente com o que é proposto no documento oficial Parâmetros Curriculares Nacionais e com as atuais orientações teóricometodológicas de ensino de língua materna no Brasil

Palavras-chave: PIBID; Pedagogia; Ensino de Língua Materna.

\section{ABSTRACT}

In this pape, we present the results of a survey in which we investigate the mother tongue teaching proposals that support degree of Projects in Education conducted under the Institutional Program Initiation Grant to Teaching in State Higher Education Institutions of São Paulo. Among the twenty-five São Paulo institutions that perform or performed projects PIBID / Pedagogy between 2009 and 2012, we identify web 12 productions that include the process of literacy and / or Portuguese language teaching in the early grades of elementary school (1st to 5th grade). The analysis showed that these productions, in most cases, the approach to the formation of the stock is very consistent with what is proposed in the official document National Curriculum Parameters and with the current theoretical and methodological guidelines of mother tongue education in Brazil.

Keywords: PIBID, Pedagogy, mother tongue teaching

\footnotetext{
1 Pedagoga e Especialista em Alfabetização e Letramento é professora do Ensino Fundamental I na rede municipal de Guaiçara (SP). Email: cristronquin@gmail.com
} 


\section{Introdução}

O trabalho aqui apresentado insere-se no contexto da pesquisa sobre a formação do professor, mais especificamente para o ensino da língua materna nos anos iniciais do Ensino Fundamental. Com vistas a contribuir para as discussões realizadas nesse campo de pesquisa, nosso objetivo principal com este trabalho foi investigar as propostas de ensino de língua materna que embasam Projetos da licenciatura em Pedagogia realizados no âmbito do Programa Institucional de Bolsa de Iniciação à Docência (daqui por diante, PIBID), em Instituições de Ensino Superior (IES) no Estado de São Paulo.

O PIBID é um programa do Governo Federal, instituído de forma ampla em 2009, por meio da Diretoria de Educação Básica Presencial da CAPES, que visa incentivar a formação de docentes em nível superior para a Educação Básica, contribuindo, assim, para a valorização do magistério e elevação da qualidade da formação inicial de professores nos cursos de licenciatura. Além disso, o PIBID objetiva promover maior integração entre a Educação Superior e a Educação Básica, inserindo os licenciandos no cotidiano de escolas da rede pública de educação, com o intuito de contribuir para a articulação entre teoria e prática necessárias à formação dos docentes e elevar a qualidade das ações acadêmicas nos cursos de licenciatura.

Nosso objetivo principal neste artigo é evidenciar os referenciais teóricos e metodológicos de ensino de língua materna que têm orientado a formação inicial dos alunos bolsistas do Curso de Pedagogia participantes do PIBID em IES do Estado de São Paulo.

Para tal, inicialmente, apresentamos as concepções teóricas e orientações metodológicas atuais de ensino de língua materna para nos anos iniciais do Ensino Fundamental (10. ao 5o. ano), bem como as orientações oficiais dos Parâmetros Curriculares Nacionais (PCNs). Na sequência, apresentamos as produções identificadas e a análise dos pressupostos teórico-metodológicos que orientam/ embasam projetos do PIBID/Pedagogia de Instituições de Ensino Superior (IES) do Estado de São Paulo, voltados especificamente ao ensino de língua portuguesa nos anos iniciais do ensino fundamental $\left(1^{\circ}\right.$. ao $5^{\circ}$. ano).

\section{1- Concepções teóricas e metodológicas para o ensino de Língua Materna no contexto brasileiro}

A partir do final da década de 60 , a nova realidade brasileira exigiu uma 
revisão dos métodos tradicionais de ensino de língua portuguesa. E essa demanda por transformações no ensino buscou no campo da Linguística novos referenciais teórico-metodológicos para embasar as propostas de mudança.

No Estado de São Paulo, no final da década de 70, estudiosos da Linguística foram requisitados pela Secretaria de Estado da Educação para a organização de um novo plano curricular para o ensino de Língua Portuguesa no Estado. Nas décadas de 80 e 90, a Proposta Curricular para o Ensino de Língua Portuguesa do Estado de São Paulo inspirou muitas Secretarias de Estado e de Municípios na produção de seus próprios currículos de Língua Portuguesa, dentre os quais, 19 foram objeto de análise em um trabalho, realizado por uma equipe de pesquisadores da Universidade Federal de Minas Gerais (UFMG), com a finalidade de oferecer ao MEC subsídios para a elaboração de parâmetros para o ensino de língua materna no Brasil. Os resultados desse estudo foram publicados por Marinho (1998).

Ao considerar os itens dos currículos que envolvem definições e conceitos teóricometodológicos, essa autora afirma que a linguagem é concebida, unanimemente, como lugar de interação entre interlocutores. Decorrente dessa concepção de linguagem, o elemento básico do ensino deixa de ser a palavra e a frase e passa a ser o texto. Nesse sentido, ressalta-se a importância de se delinear uma concepção de texto como uma unidade de sentido determinada pela situação de interação.

Tendo em vista esses pressupostos, ao analisar as questões de produção e de recepção dos textos, Marinho observa que a função da leitura e da escrita, nos currículos, se traduz, principalmente, "por uma lista de tipos de textos que circulam na sociedade, sem que se explicite que função sociocomunicativa cumpriria na escola, embora sirvam como modelos para o aprendizado da escrita". (MARINHO, 1998, p.75)

Segundo Marinho, a ausência de uma perspectiva sobre as práticas sociais da leitura e da escrita e dos seus processos cognitivos provavelmente tenha produzido uma associação, quase que mecânica, entre tipos de texto e processamento da leitura e da escrita. Ainda para essa autora, a proposta de um trabalho com a diversidade textual parecer ser, do ponto de vista dos currículos analisados, a tentativa de resolver a preocupação com os usos sociais da língua.

A partir dessas observações, a noção de texto como parâmetro para a definição dos conteúdos, objetivos e estratégias de ensino-aprendizagem da leitura e da escrita vem indiciar, de acordo com Marinho, a necessidade e a dificuldade de se tomar o texto como recorte linguístico básico do processo de ensino/aprendizagem, numa concepção discursiva ou interativa da linguagem. 
De fato, como ressalta a autora, tem sido difícil encontrar, na escola, "situações menos artificiais de relação com os textos, para que o aluno vivencie a atividade de interação verbal da forma mais variada possível. Por isso é que se vê uma mera transposição para a escola de textos socialmente produzidos". (MARINHO, 1998, p.81).

Koch e Bentes (1999), ao desenvolverem uma reflexão sobre a produção textual na escola, também observam que a concepção de linguagem como prática social e, portanto, lugar de interação entre sujeitos sociais, não tem chegado, da forma como seria desejável, à escola. Segundo essas autoras, para que se possa considerar a linguagem como prática social, é preciso ter em mente que as interpretações feitas pelos agentes da situação são essenciais. Nos termos de Koch e Bentes (1990, p.16), essas interpretações dependem de dois fatores, a saber: "a) da identidade social dos atores; b) das representações que eles têm dos usos possíveis da linguagem e das funções que os atores privilegiam de acordo com sua trajetória". Estudar o funcionamento linguístico como práticas sociais significa, então, para as autoras, analisar as diferenças e variações em função de sistemas de categorizações sociais à disposição dos sujeitos observados.

Dessa forma, inspiradas em Bakhtin (1992), Koch e Bentes defendem que todos os nossos enunciados baseiam-se em formas padrão e relativamente estáveis de estruturação de um todo. "Tais formas constituem os gêneros, tipos relativamente estáveis de enunciados, marcados sócio-historicamente, visto que estão diretamente relacionados às diferentes situações sociais". (KOCH e BENTES, 1999, p.18) Nesse sentido, a discussão sobre os gêneros do discurso pode trazer contribuições relevantes para a mudança da forma de tratamento da compreensão e da produção textual na escola.

Foi, certamente, a partir de reflexões como essas que, no final da década de 90, a elaboração dos Parâmetros Curriculares Nacionais de Língua Portuguesa para o $3^{\circ}$ e $4^{\circ}$ ciclos (doravante PCNs), recuperando as Propostas Curriculares Estaduais e procurando corrigir os rumos do ensino de Língua Portuguesa, adotou os gêneros textuais como objeto de ensino.

Os gêneros do discurso são definidos por Bakhtin (1992, p. 281) como tipos relativamente estáveis de enunciados. O enunciado, segundo esse autor, se caracteriza por seu conteúdo temático; por seu estilo verbal (seleção operada nos recursos da língua como recursos lexicais, fraseológicos e gramaticais); por sua construção composicional.

De acordo com Bakhtin, a riqueza e a variedade dos gêneros do discurso são 
infinitas, pois a variedade virtual da atividade humana é inesgotável, e cada esfera dessa atividade comporta um repertório do discurso que vai diferenciando-se e ampliando-se à medida que a própria esfera se desenvolve e fica mais complexa.

Bakhtin salienta a heterogeneidade dos gêneros do discurso (orais e escritos), incluindo indiferentemente, desde o diálogo cotidiano, o relato familiar, a carta, até as variadas formas de exposição científica e todos os modos literários. Além disso, Bakhtin assume a extrema dificuldade para se definir o caráter genérico do enunciado diante dessa heterogeneidade dos gêneros do discurso.

Assim, para melhor explicitação dessas questões e sem qualquer pretensão de aplicação didática, o autor propõe uma distinção entre gênero de discurso primário (simples) e gênero de discurso secundário (complexo). Como ratifica no trecho transcrito abaixo:

Os gêneros secundários do discurso - o romance, o teatro, o discurso científico, o discurso ideológico, etc. - aparecem em circunstâncias de uma comunicação cultura, mais complexa e relativamente mais evoluída, principalmente escrita: artística, científica, sociopolítica. Durante o processo de sua formação, esses gêneros secundários absorvem e transmutam os gêneros primários (simples) de todas as espécies, que se constituíram em circunstâncias de uma comunicação verbal espontânea. Os gêneros primários, ao se tornarem componentes dos gêneros secundários, transformam-se dentro destes e adquirem uma característica particular: perdem sua relação imediata com a realidade existente e com a realidade dos enunciados alheios (BAKHTIN, 1992, p. 281).

$\mathrm{Na}$ opinião de Bakhtin, a distinção entre gêneros primários e gêneros secundários tem grande importância teórica na medida em que a natureza do enunciado é elucidada e definida por uma análise de ambos os gêneros e somente com essa condição "a análise se adequaria à natureza complexa e sutil do enunciado e abrangeria seus aspectos essenciais." (BAKHTIN, 1992, p.282) A inter-relação entre os gêneros primários e secundários de um lado, o processo histórico de formação dos gêneros secundários de outro, é o que esclarece, na visão de Bakhtin, a natureza do enunciado e o difícil problema da correlação entre língua, ideologia e visões do mundo.

Já de um ponto de vista mais voltado para a aplicação didática, Schneuwly e Dolz (2004, p. 52) asseguram que os gêneros textuais, por seu caráter genérico, podem ser um termo de referência intermediário para a aprendizagem. Segundo esses autores, "do ponto de vista do uso e da aprendizagem, o gênero pode, 
assim, ser considerado como uma mega-ferramenta que fornece um suporte para a atividade nas situações de comunicação e uma referência para os aprendizes."

Para tanto, ou autores partem da hipótese de que "é através dos gêneros que as práticas de linguagem materializam-se nas atividades dos aprendizes". (SCHNEUWLY E DOLZ, 2004, p. 74) Assim, os autores entendem o domínio do gênero como o próprio domínio da situação comunicativa, e esse domínio podese dar através do ensino das capacidades de linguagem, ou seja, pelo ensino das aptidões exigidas para a produção de um gênero determinado.

$\mathrm{Na}$ visão desses mesmos autores, a situação escolar apresenta uma particularidade pelo fato de que na escola há um desdobramento que se opera, em que o gênero não é mais ferramenta de comunicação somente, mas ao mesmo tempo, objeto de ensino/aprendizagem. Em síntese, o gênero pode ser utilizado como meio de articulação entre as práticas sociais e os objetos de ensino. A questão que se coloca, então, é: como introduzir o gênero na escola?

Para Schneuwly e Dolz toda introdução de um gênero na escola é o resultado de uma decisão didática que visa objetivos precisos de aprendizagem que são sempre de dois tipos:

a) aprender a dominar o gênero, primeiramente, para melhor conhecê-lo ou apreciá-lo, para melhor saber compreendê-lo, produzi-lo na escola ou fora dela; para desenvolver capacidades que ultrapassam o gênero e são transferíveis par outros gêneros próximos ou distantes. Para atingir tais objetivos é preciso haver uma transformação, ao menos parcial, do gênero: simplificação, ênfase em determinadas dimensões, etc.

b) colocar os alunos, ao mesmo tempo, em situações de comunicação que sejam o mais próximas possíveis de verdadeiras situações de comunicação, que tenham um sentido para eles a fim de melhor dominá-las como realmente o são, sabendo o tempo todo que os objetivos visados são (também) outros.

Desse modo, para compreender bem a relação entre os objetos de linguagem trabalhados na escola e os que funcionam como referência, é preciso, nos termos desses autores, "partir do fato de que o gênero trabalhado na escola é sempre uma variação do gênero de referência, construída numa dinâmica de ensino/aprendizagem, para funcionar numa instituição cujo objetivo primeiro é, precisamente, este". (SCHNEUWLY E DOLZ. 2004, p.76)

Essa perspectiva é assumida pelos Parâmetros Curriculares Nacionais: Língua Portuguesa (PCN). Os PCN voltados para os anos iniciais do Ensino 
Fundamental foram publicados em 1997 e defendem que o ensino se desenvolva a partir de dois eixos: um que enfoca as práticas de uso da língua por meio das práticas de escuta, leitura e produção de textos orais e escritos; e outro que enfoca as práticas de reflexão sobre a língua por meio da prática da análise linguística.

Quanto aos conteúdos gerais dos ciclos ( $1^{\circ}$. a $4^{\mathrm{a}}$. Séries; atualmente de $1^{\circ}$. ao $5^{\circ}$. ano), estes são divididos no documento em duas partes: a primeira diz respeito a valores, norma e atitudes; a segunda parte aos gêneros discursivos. No primeiro momento, estão descritos os conteúdos atitudinais, que visam desenvolver nos alunos as capacidades atitudinais, tais como: manuseio responsável dos livros, respeito à variação linguística, valorizar a leitura como fonte de entretenimento, incentivo a empréstimo de livros nos acervos das bibliotecas, interesse a explorar a dimensão estética da linguagem, entre outros.

No que se refere ao trabalho com os gêneros textuais, há uma divisão em dois grupos: gêneros adequados para trabalhos com a linguagem oral e gêneros adequados para trabalhos com a linguagem escrita.

De acordo com os PCN, os gêneros textuais que devem ser trabalhadas para desenvolvimento da linguagem oral são: contos poemas, canções, quadrinhas, parlendas, adivinha, trava-línguas, piadas, provérbios, saudações, instruções, relatos, entrevistas, debates, notícias, seminários e palestras.

Já para o desenvolvimento da linguagem escrita, o documento orienta a se trabalhar com os seguintes gêneros textuais: cartas, bilhetes, postais, cartões, quadrinhos, textos de jornais, revistas, anúncios, slogans, cartazes, folhetos, contos, lendas, fabulas, folhetos de cordel, textos teatrais, relatos históricos, textos de enciclopédia, verbetes de dicionário, adivinhas, entre outros.

Em síntese, os PCN acentuam a necessidade de privilegiar a diversidade de textos e gêneros nas atividades de ensino, considerando-se os papéis sociais dados pelas condições de produção e as diferentes formas de organização dos gêneros. Além disso, os princípios norteadores do ensino de língua portuguesa nos PCN, a ideia da progressão didática e os critérios para a sequenciação dos conteúdos são aspectos que representam um grande avanço em relação às orientações metodológicas apresentadas nas últimas décadas para esse ensino.

Vejamos a seguir a IES paulistas que participam do PIBID/Pedagogia e as características das produções que encontramos relacionadas ao ensino de língua materna. 


\section{2- Levantamento e Análise dos dados da pesquisa}

Primeiramente, realizamos o levantamento das IES do Estado de São Paulo participantes do PIBID entre 2009 e 2012 . Identificamos 33 IES, dentre as quais apenas 25 realizam ou realizaram projetos na área de Pedagogia dentro do período considerado.

Em seguida, buscamos informações sobre esses projetos disponibilizados na $w e b$ pelas IES, em sites das IES e em produções científicas publicadas em Anais de eventos do PIBID realizados no Estado de São Paulo e disponíveis na web.

Nessa busca, constatamos que há muito pouco material ou produção relativa ao PIBID disponível na web. Ainda assim, conseguimos identificar 12 produções que contemplam a formação dos bolsistas de Pedagogia para o ensino de língua materna, ou seja, aspectos relacionados ao processo de alfabetização e letramento/ leitura e produção escrita no ensino de língua portuguesa nos anos iniciais do Ensino Fundamental (10. ao 5o. ano).

Analisamos, então, 12 (doze) produções, assim subdivididas: 03 (três) subprojetos de Pedagogia, 08 (oito) resumos e 01(um) artigo. Para a análise, seguindo a metodologia da Análise de Conteúdo (FRANCO, 2007) estabelecemos as seguintes categorias: Concepções Teóricas, Orientações Metodológicas e Conteúdos.

No primeiro momento, fizemos uma análise individualizada de cada produção, para, em seguida, detalharmos cada um dos itens supramencionados em uma análise global.

Documento 01 - Subprojeto de Pedagogia da Universidade A

Concepções Teóricas:

$\mathrm{Na}$ análise do subprojeto de pedagogia da Universidade $\mathrm{A}$, não foi possível identificar elementos suficientes para afirmarmos qual o referencial teórico adotado pelo subprojeto. A única forma encontrada foi analisarmos a referência bibliográfica utilizada, o que nos permite afirmar que o embasamento desse subprojeto são os PCN, pois em um pequeno fragmento, extraído do texto ("justifica-se pela necessidade incessante de se (re)pensar o ensino da leitura, da escrita e da alfabetização e seus processos de aprendizagem nos anos iniciais"), observa-se a preocupação do projeto com as orientações mais atuais de alfabetização, leitura e escrita. 
Orientações Metodológicas:

Os alunos bolsistas colaboram com as atividades de alfabetização nas escolas, elaborando materiais didáticos em alfabetização, estimulando o acesso a bibliotecas escolares e aos materiais didáticos elaborados pelas equipes pedagógicas nas escolas contempladas, além de incentivar a produção de diversos gêneros textuais, sempre relacionando com o seu uso social.

A literatura também é contemplada no projeto como uma forma de compreensão da função social da escrita, por meio da leitura de obras literárias infantis, clássicas ou contemporâneas.

Os alunos bolsistas participam de reuniões mensais onde apresentam seus relatórios ao professor coordenador, e ao professor da unidade escolar. São nessas reuniões que são orientados para criarem oficinas pedagógicas, visando à análise, avaliação e reformulação de propostas didáticas sobre alfabetização recorrentes na escola.

Conteúdos:

Não foi possível com a leitura e análise do documento, relacionarmos os conteúdos trabalhados nesse projeto.

Documento 02 - Análise do Subprojeto Universidade B

Concepções Teóricas:

Analisando o subprojeto da Universidade B, podemos inferir que o embasamento teórico mais presente refere-se à adequação da organização escolar à forma com que os alunos constroem o conhecimento. Como ratifica trecho extraído do documento analisado: “[...]diante das novas diretrizes para o Ensino Fundamental, que passa a contar com 9 anos de escolaridade, sendo 6 anos a idade de ingresso dos alunos. Tal situação exige uma reorganização da estrutura escolar. $[\ldots] "$.

O subprojeto não disponibiliza referência bibliográfica, porém fica clara a utilização dos $\mathrm{PCN}$ e a presença dos teóricos Emília Ferreiro, em relação às concepções teóricas de Alfabetização e Letramento, e do autor Vygostsky, na teoria do desenvolvimento da criança.

Orientações Metodológicas: 
No decorrer da leitura desse documento, podemos observar que a abordagem metodológica prevê uma articulação entre os professores da Universidade B, professores e Supervisores da equipe de gestão das escolas parceiras e alunos bolsistas da licenciatura de Pedagogia, buscando com este tripé uma abordagem participativa no ambiente escolar, visando à melhoria da qualidade do ensino.

As ações previstas nesse subprojeto iniciam-se pelo planejamento do trabalho na escola, por meio de uma aproximação da realidade da vida escolar, assim podendo desenvolver atividades mais significativas para o uso social dos alunos. Essas ações são discutidas em encontros semanais e mensais, para análise coletiva das observações e registros feitos pelos bolsistas junto com professores supervisores e professor coordenador do subprojeto de Pedagogia.

Conteúdos:

Não foi possível, com a leitura e análise do documento, identificar os conteúdos trabalhados nesse projeto.

\section{Documento 03 - Análise do Subprojeto Universidade C}

\section{Concepções Teóricas:}

O subprojeto de pedagogia da Universidade C tem como embasamento teórico a obra de Paulo Freire "Pedagogia da Autonomia". Durante a leitura do documento constatamos por diversas vezes a citação do referido livro. A grande preocupação explicitada no projeto é de uma educação como uma forma de intervir no mundo, e que os docentes precisam adequar a sua atuação desde a sua formação inicial. A única obra citada na referência bibliográfica é a Pedagogia da Autonomia de Paulo Freire, assim ratificando as concepções teóricas encontras no subprojeto.

Orientações Metodológicas:

As metodologias que pudemos constatar com a leitura realizada do documento são "Reflexões dos dados coletados", dados esses que são adquiridos através dos seus registros de atuação.

As ações descritas no subprojeto realizadas pelos alunos bolsistas são: Analisar a usabilidade das atividades lúdicas, recreativas, em especial para os avanços da aprendizagem escolar; preparar material didático para práticas 
pedagógicas que estimulem o ato de ler, escrever e solucionar problemas matemáticos ou não, bem como analisar a utilização dos mesmos; promover entre os participantes do projeto possibilidade de debates e difusão de conhecimento adquirido por meio de apresentações orais em congressos, workshops e publicações no meio acadêmico.

O principal objetivo da Instituição é o de fazer com que o docente reflita sobre a sua ação, se conscientize da importância da pesquisa contínua, levando-o a uma formação de qualidade.

Conteúdos:

Não foi possível, com a leitura e análise do documento, identificar os conteúdos trabalhados nesse projeto.

Documento 04 - Resumo 01 da Universidade D

Concepções Teóricas:

Com a leitura desse documento, foi possível identificar que a concepção teórica de embasamento é o PCN, pois mesmo não estando citado, percebemos em alguns momentos a preocupação com a integração dos educandos à sociedade, ponto este vastamente discutido no documento.

Orientações Metodológicas:

As orientações metodológicas empregadas foram: leitura e produção de textos verbais, imagéticos, pictóricos e fílmicos; interpretação e compreensão de textos e análise da estrutura dos gêneros textuais: história em quadrinhos, filme e carta.

Conteúdos:

Os conteúdos trabalhados foram: estrutura dos gêneros textuais: história em quadrinhos, filme e carta; e leitura e produção de textos verbais de diferentes gêneros.

Documento 05 - Resumo 02 da Universidade D

Concepções Teóricas: 
A concepção teórica que embasa esse trabalho, mesmo que não explicitamente, é o referencial que embasa os PCN, sendo que em várias passagens do texto percebemos a importância dada à leitura como inserção do indivíduo no contexto social ao qual pertence.

Orientações Metodológicas:

As orientações metodológicas empregadas foram: comunicação verbal; reflexão sobre as estruturas do gênero textual: parlenda; compreensão das diferenças entre a linguagem oral e escrita; e sondagem das hipóteses da escrita dos alunos.

Conteúdos:

Os conteúdos desenvolvidos nesse trabalhado foram: estrutura de gênero textual parlenda; comunicação verbal; e linguagem oral e escrita.

Documento 06: Resumo 03 da Universidade D

Concepções Teóricas:

Percebemos que a concepção de leitura presente nesse documento é a de leitura como construção de sentidos, embasada nas perspectivas dos gêneros textuais e habilidades de leitura, conforme orientações dos descritores da matriz da prova Brasil.

Orientações metodológicas:

Constatamos, a partir da leitura do documento, que as orientações metodológicas implementadas neste trabalho são: leitura em voz alta, identificação de ritmos, seleção de diversos gêneros textuais que tematizam as diversas culturas. Conteúdos:

Foram trabalhados nesse projeto os seguintes conteúdos: estrutura de gêneros textuais, leitura em voz alta e a leitura e compreensão dos textos.

Documento 07 : Resumo 04 da Universidade D

Concepções Teóricas: 
Constatamos, com a análise desse documento, que a concepção de leitura encontrada vai ao encontro das orientações dos PCN, pois nesse documento a leitura é vista como prática social essencial para a vivência plena da cidadania e inserção social, sendo que a escola tem papel fundamental nesse processo.

Orientações metodológicas:

Constatamos a partir da leitura do documento que as orientações metodológicas implementadas nesse trabalho são: leitura em voz alta; trabalho com o gênero textual: Conto; pesquisa de significado de palavras africanas.

Conteúdos:

Foram trabalhados nesse projeto os seguintes conteúdos: estrutura do gênero textual conto, leitura em voz alta e a leitura e compreensão dos textos.

Documento 08 : Resumo 05 da Universidade D

Concepções Teóricas:

As concepções teóricas que embasam esse trabalho são dos gêneros textuais, defendida pelos autores Schneuwly e Dolz, embora não apareçam citações explícitas, é possível inferir, no trecho extraído do documento, a importância de se trabalhar com diversos gêneros textuais: "[...] incentivar a aproximação e o gosto pela leitura nos alunos, oportunizando atividades com diferentes gêneros textuais $[\ldots] "$.

Podemos afirmar que esse trabalho está também sendo embasado pelos PCN de Língua Portuguesa, uma vez que o documento oficial defende essa mesma linha de ensino de língua materna.

Orientações metodológicas:

Percebemos, com a leitura, que a orientação metodológica segue as seguintes estratégias: leitura feita pelo professor, roda de conversa, atividades com registro de rimas de palavras retiradas do texto, e produção de texto individual com leitura em voz alta.

Conteúdos:

Foram trabalhados nesse projeto os seguintes conteúdos: estrutura de gêneros textuais diversos, leitura e compreensão dos textos e leitura em voz alta. 
Documento 09 - Resumo 06 da Universidade D

Concepções Teóricas:

Com a leitura do documento, é possível identificar a presença dos descritores usados na avaliação da Prova Brasil, como no trecho a seguir:

Oportunizar situações em que as crianças vivenciem atividades individuais ou coletivas com as quais poderão exercitar com maior habilidade e desenvoltura a sua leitura e escrita; poderão, também, avançar ou retroceder durante a leitura em busca de informações esclarecedoras, fazer inferências e atribuir sentidos a partir de suas experiências. (BRASIL, p. 26

Além de percebemos o trabalho com os descritores da Prova Brasil, identificamos a concepção dos gêneros textuais, defendida pelos autores da Escola de Genebra, Schneuwly e Dolz.

\section{Orientações Metodológicas:}

Como orientação metodológica, constatamos a utilização de diversos textos, músicas e contos diversos de várias regiões para fazer com que os alunos identificassem e comparassem diversas culturas. Percebemos a utilização do projeto de leitura para também se trabalhar a diversidade cultural, pretendendo assim favorecer o hábito da leitura e fazendo com que os alunos conheçam diversos gêneros e se tornem críticos em sua vida social.

Conteúdos:

Nesse projeto foram trabalhados os seguintes conteúdos: estrutura de gêneros textuais diversos, leitura e compreensão dos textos e leitura em voz alta.

Documento 10: Resumo 01 da Universidade E

Concepções Teóricas:

As concepções teóricas desse trabalho são embasadas nos pesquisadores da Escola de Genebra (Dolz e Schneuwly) para elaboração de sequência didática de gêneros textuais e a investigação didática da autora argentina Delia Lerner.

Orientações metodológicas: 
Constatamos, a partir da leitura do documento, que as orientações metodológicas implementadas nesse trabalho foram de articulação do trabalho com as sequências didáticas com o Projeto Político Pedagógico da Escola, buscando dar significado ao aprendizado do aluno.

Conteúdos:

Nesse projeto foram trabalhados os seguintes conteúdos: estrutura de gêneros textuais: carta, convite e entrevista.

Documento 11 - Resumo 02 da Universidade E

\section{Concepções Teóricas:}

As concepções teóricas que embasam esee projeto da Universidade são: Engenharia didática (ARTIGUE, 1996), investigação didática (LERNER, 2002) orienta-se também pela abordagem dos pesquisadores da escola de Genebra (SCHNEWULY E DOLZ, 2004), para a elaboração de sequência didática de gêneros textuais no ensino da Língua Portuguesa, além da concepção de Avaliação Diagnóstica (DOLZ, DECANDIO e GAGNON, 2010).

Orientações Metodológicas:

As orientações metodológicas empregadas nesse projeto foram planejamento e desenvolvimento de sequência didática sobre o gênero convite. Discussão oral sobre o gênero convite e confecção do convite.

Conteúdos:

Nesse projeto foram trabalhados os seguintes conteúdos: estrutura de gêneros textuais convite e linguagem oral.

Documento 12 - Artigo 01 da Universidade E

Concepções Teóricas:

A concepção teórica que embasa o projeto baseia-se no autor Zabala (1998). Este teórico defende que a formação docente amadurece durante a prática, 
portanto, não basta somente a formação inicial, o professor deve atuar para adquirir experiências e conhecimentos. Como ratifica trecho abaixo extraído do documento:

(...) é necessário que a formação dos professores esteja estreitamente relacionada à prática real da sala de aula. No fundo, ensinar implica dominar habilidades, técnicas e estratégias de ensino, isto é, domínio de procedimentos. Do mesmo modo que se aprende a dançar dançando, aprende-se ensinar ensinando. Ao contrário, a maioria dos cursos de formação de professores está ligada ao discurso teórico e como sabemos, este tem muito pouca valia se não estiver relacionado, antes de tudo, a exemplos, ou seja, a modelos. (ZABALA, 1998, p. 65)

\section{Orientações Metodológicas:}

No documento existe uma divisão em dois grandes momentos. Na orientação metodológica, no primeiro momento, os alunos bolsistas fizeram registros com análise de suas próprias reflexões, também desenvolveram atividades como apoio escolar nas áreas de alfabetização e matemática e atuaram na biblioteca tutorada, isto é, como orientadores de leitura na biblioteca. Já no segundo momento, os licenciandos de Pedagogia fizeram apoio de língua portuguesa para o segundo ciclo do ensino fundamental I, além de apoio em matemática, planejamento de atividades dirigidas e continuaram a participar da Biblioteca tutorada.

Conteúdos:

Com a leitura do documento 12, não foi possível identificar quais os conteúdos trabalhados.

Como mencionamos anteriormente, fizemos uma explanação de cada item analisado dos documentos. Esta análise se fez necessária para reconhecermos o que há de recorrente e as peculiaridades dos documentos.

No item concepções teóricas, o documento oficial PCN é reconhecido em 9 (nove) de 12 (doze) documentos analisados, já a concepção de gêneros textuais, defendida pelos teóricos da escola de Genebra, está presente em 4 (quatro) de 12(doze) documentos; outras concepções teóricas que aparecem em 2 (dois) documentos são: engenharia didática, descritores da matriz da prova Brasil e sequência didática. E, por fim, sendo mencionados apenas 1(uma) vez aspectos relativos à avaliação diagnóstica e formação de professor.

As orientações metodológicas dos documentos analisados não evidenciaram muitas variações nas estratégias de ensino apresentadas nos documentos, todas colocam a figura do professor como mediador do conhecimento; em apenas um 
dos documentos analisados, pudemos constatar a preocupação de articular o PPP (Projeto Político Pedagógico) com a sequência didática realizada em sala de aula.

No que se refere aos conteúdos, em todos os documentos que conseguimos identificar os conteúdos trabalhados em sala de aula, a concepção dos gêneros textuais é utilizada, além de comunicação oral, produção de textos orais e escritos, interpretação e compreensão de textos orais e escritos e leitura feita pelo professor e em voz alta.

\section{Considerações Finais:}

Como foi mencionado no corpo da pesquisa, identificamos trinta e três universidades no Estado de São Paulo que participam do PIBID, sendo que vinte e cinco possuem o PIBID na licenciatura em Pedagogia. Porém, no período considerado neste trabalho 2009 a 2012, apenas cinco dentre essas Universidades disponibilizaram suas produções na Web, por este motivo, conseguimos apenas doze documentos para análise. Este número é relativamente baixo, por se tratar de um programa relevante para a formação do futuro professor.

Com relação a um dos objetivos principais do PIBID - antecipar o vínculo dos licenciandos do curso de pedagogia às escolas públicas de educação básica no caso dos projetos PIBID/Pedagogia nas IES do Estado de São Paulo, voltados ao ensino da língua materna, parece-nos que está sendo contemplado. Além de levar aos professores em exercício a interagir, de forma mais próxima com a Universidade, revendo sua formação. Portanto, podemos concluir que no tripé de sustentação do PIBID - Escola pública, professor da rede e os licenciandos - todos saem do programa com um ganho efetivo.

Por fim, a análise de como está sendo trabalhada a Língua Materna na escola de Educação Básica dentro do programa evidencia que a abordagem adotada para a formação dos bolsistas está coerente com as principais orientações dos PCN: o ensino da língua deve ser realizado contextualizando situações reais do cotidiano da criança, trabalhando os gêneros textuais, por meio de sequências didáticas.

\section{Referências}

ARTIGUE, M. Engenharia Didática. In: BRUN, Jean (Org). Didática das Matemáticas. Trad. Maria José Figueiredo. Delachaux et Niestlé, 1996.

BAKHTIN, M. Estética da Criação Verbal. São Paulo: Martins Fontes, 1992. DOLZ, J.; GAGNON, R. \& DECÂNDIO, F. R. Produção escrita e dificuldades de aprendizagem. Campinas: Mercado de Letras, 2010.

FRANCO, Maria Laura Puglisi Barbosa. Análise de conteúdo. 2. ed. Brasília: 
Liver Livro, 2007.

FREIRE, P. Pedagogia da autonomia: saberes necessários à prática educativa. 25. ed. São

Paulo: Paz e Terra, 1996. (Coleção leitura).

KOCH, Ingedore, G. V.; BENTES, A. C. Os gêneros do discurso e a produção textual na escola. UFPA/UNICAMP. Brasil, São Paulo: Série Intercâmbio. PUC, 1999.

LERNER, Delia. Ler e escrever na escola: o real, o possível e o necessário. Porto Alegre: Artmed, 2002.

MARINHO, M. A Língua Portuguesa nos currículos de final de século. In: BARRETO, E. S.

(org) Os Currículos do Ensino Fundamental para as escolas brasileiras. Campinas: Editora Autores Associados, 1998, pp.43-90.

SCHNEUWLY. B e DOLZ, J. Gêneros orais e escritos na escola. Campinas (SP): Mercado das Letras, 2004.

TARDIF, M. Saberes docentes \& formação profissional. 4. ed. Petrópolis: Vozes, 2002.

ZABALA, A. A prática educativa: como ensinar. Porto Alegre: Artes Médicas, 1998. 